\title{
Venture Investment Incentive Mechanisms and Simulation with Venture Entrepreneurs Having Multistage Efforts Based on Fairness Preference Theory
}

\author{
Kaihong Wang, ${ }^{1}$ Chuan Ding, ${ }^{1}$ Jiacheng Chen, ${ }^{2}$ and Aimin $\mathrm{Li}^{1}$ \\ ${ }^{1}$ Research Institute of Financial Mathematics, Southwestern University of Finance and Economics, Chengdu 610074, China \\ ${ }^{2}$ School of Finance, Southwestern University of Finance and Economics, Chengdu 610074, China \\ Correspondence should be addressed to Chuan Ding; dingchuan@swufe.edu.cn
}

Received 5 April 2016; Accepted 19 July 2016

Academic Editor: Paolo Renna

Copyright (C) 2016 Kaihong Wang et al. This is an open access article distributed under the Creative Commons Attribution License, which permits unrestricted use, distribution, and reproduction in any medium, provided the original work is properly cited.

\begin{abstract}
When venture capital has been invested into venture companies, venture capitalists and venture entrepreneurs form a principalagent relationship. Take into account the fact that the venture entrepreneur's effort is a long process, because the effort is not the same at different stage. Therefore, efforts variables are seen as the multistage dynamic variable, and venture investment principalagent model with venture entrepreneurs having multistage efforts is constructed on the basis of the classic principal-agent theory in the paper. Further, in the later stage effort of venture entrepreneurs is affected by the size of prestage benefit with venture capitalists and venture entrepreneurs; thus the fairness preference model is improved, and venture investment principal-agent model with venture entrepreneurs having multistage efforts is constructed on the basis of fairness preference theory. Both theoretical derivation and simulation have demonstrated that, under the condition of information asymmetry, if the fairness preference of venture entrepreneurs holds, then (1) venture capitalists provide venture entrepreneurs with level higher than that without fairness preference, (2) in every single stage venture entrepreneurs make efforts higher than those without fairness preference, and (3) in two periods both venture investors and venture entrepreneurs gain total real gains higher than those in two periods without fair preference.
\end{abstract}

\section{Introduction}

In general, venture capital investment or start-up investment is a way of venture capitalists investing their venture capital in a venture business. By joining in the operation, management, and the consulting service, venture capitalist (later shown as $\mathrm{VC}$ ) promotes the venture business to become a large scale corporation and then sell their holdings to share the long-stage capital appreciation of the business's fast expansion. Three main subjects are involved during the process of a venture-financing: a venture investor, a $\mathrm{VC}$, and an entrepreneur (later shown as EN). Among the three subjects, investor and the $\mathrm{VC}$ are major participants. In the process of a venture-financing, investor plays the core roles, which are the source of venture capital. Then the venture capital flows to a venture capital institution and, after the selection of VC, goes to the venture business. After the business's operation, the capital grows larger and then flows back to the venture capital institution. After that, the return is repaid to investors and thus forms a capital circulation and the dual principleagent relationships. One is between investors and the venture capitalist, while the other is between the venture capitalist and the entrepreneur. The principle-agent relationship between the $\mathrm{VC}$ and the $\mathrm{EN}$ is of key importance among the whole capital circulation, for it is related to venture capital's value maintenance and appreciation. During the initial process of investment, $\mathrm{VC}$ is not aware of the EN's operating talents, his efforts, and the profit and risk situation. The EN knows this fact and thus always makes decisions by maximizing his personal utility, always reduces efforts, overuses the venture capital, and does over investments. These behaviors lead to the moral hazard between the EN and the VC.

This paper thus focuses on the principle-agent relationship between the VC and EN and on how to prevent or lower the moral hazard. Current researches have focused adequately on this relationship [1-13]. The themes of these 
researches can be concluded as follows. First is about the feasible incentive mechanism design related to reducing the moral hazard. The design work is expected to motivate EN to make efforts and thus increase VC's utilities, to adopt negotiating mechanism to realize mutual benefit-sharing and risk-taking approaches. For example, Ying and Zhao [13], from the perspective of VC, have concluded the dual principle-agent relationship and designed a mechanism to maximize the utilities of venture capital investors. Sahlman [14] believes that VC must enforce incentive constraint to EN based on observed information to unify the expected interest of the two groups of people. Shliefer and Vishy [15] have put out that, to a certain degree, by concentrating the control power on the minor large stockholders, investors interests can be protected, but this may easily lead to insider control. Second is the exploration into the historical achievement, the reputation, or the potentials of the EN. For example, Chan et al. [10] think that adverse selection issue can be partially solved by looking into the EN's historical performance, but this needs a complete performance evaluation system to assess the objectiveness and fairness of the venture capital investment market. Jin et al. [11] hold the point that the degree of staged effort, affected by reputation, is strictly greater than the degree without such affection, and the longer the affection remains, the greater the incentive effort to the EN is. Xu et al. [12] believe that both reputation and control power are the crucial components of venture capital incentive mechanism and thus explored the reputation effects on the incentive mechanism focusing on the control power to venture capital. This exploration is put out in three dimensions separately: stock, bonds, and convertible preferred stocks. Ai et al. think that, under the reputation incentive mechanism, the relative performance ratio is beneficial to solving the information asymmetry between $\mathrm{VC}$ and $\mathrm{EN}$ and is of positive directional use in completing the investment contract [16].

Researches above have focused on the efforts of entrepreneurs that affect the value of businesses, but most are done in the static dimension. Only a limited number of scholars have focused on the dynamic efforts: Jin et al. [11] have researched VC's two-staged finance issue by supposing that each stage's production function is the function of effort in the according stage. Elitzur and Gavious have researched on the relationship between the venture investors and EN with a multistaged gaming model based on moral hazard. Based on the EN's efforts, they designed a multistaged incentive contract that prevents moral hazard [17]. Their results have showed that VC should delay the incentive to EN as late as possible, and debt contract is the optimal. Because Elitzur and Gavious have only considered the EN's moral hazards, thus the moral hazards from the VC are ignored. By taking the bilateral moral hazard and different effort the EN and VC into consideration, Zhang and Wei have improved the model of Elitzur and Gavious. They thus deduced the optimal incentive compensation model between VC and EN and analyzed certain factors affecting the contract's design and came up with the VC's best quitting point [18]. Arcot develops multistage model and shows that the participation and convertibility features of PCP stock can be used to reduce information asymmetry between the venture and potential investors at the time of exit. Further, the convertibility feature of PCP helps in alleviating the problem of insufficient entrepreneurial effort [19]. For other related studies, see [20].

However, these multistage venture capital researches are all based on a fundamental assumption: VC and EN are completely rational. Recent studies have doubted this hypothesis, believing that not all individual behaviors can be explained by the new classical economics' utility maximization and that sometimes these explanations are different from the "real world." Kahneman et al. have also believed that businesses also care about fairness, for it is crucial role in establishing and maintaining relationships [21]. This, in fact, is the fairness preference issue in behavioral finance, and the ultimatum game, dictator game, gift-exchanging game, and trust game have funded the output of nonutility maximizing. To theorize this result, many researchers have designed some fair preference model. These models can be separated into two categories. One category believes that people care about whether the final result of distribution is fair. Participants care about both the material interest they have and the material interest others have. The character of this model is the supposition that the related bodies face a trade-off between their own interest and others' interest. That is to say an individual must weigh his own material interest and the fairness of distribution result. To show both individual interest and others' interests, Fehr and Schmidt have put out a simple linear utility function model [20]. Another category thinks that if one side believes that the other side is well-meant, then he will repay; otherwise if he believes that the other side is malicious, he will revenge [22]. This result provides powerful explanation to altruistic behaviors and collaboration.

This paper innovates in the application of the theory above to the investment relationship between VC and EN. Currently, few Chinese papers apply fairness preference theories to investment researches. Feng et al. believe that, in venture investment market, VC and EN, especially VC, often show bounded rationality. Apart from profit, VC may have taken individual entertainment demand and personal fairness preference into account. They are looking for a satisfied solution, rather than the ultimate solution [23]. Aimed at VC and investors who obtain fair psychological preference, Li and Zhou have built a new paying model. By designing an effective incentive mechanism, they provide accordance to establishing a feasible paying contract [24]. But their research did not consider multistages. In reality we find a phenomenon: a decision-maker will be affected by previous profit when making different efforts. If higher previous (the $k-1$ stage) profit is obtained, then in later stage (the $k$ stage) the decision-maker will put out more efforts; if lower previous (the $k-1$ stage) profit is obtained, then in later stage (the $k$ stage) he will lack the initiative to work hard, which means that the decision-maker will make less efforts. To conclude, this means that VC will compare the profit in the $k$ stage with the profit in the $(k-1)$ stage. This, in fact, is another statement of fairness preference theory. In relation to the contents above, this paper adopted a different fairness preference theory from the ones of Fehr and Schmidt (the fair preference theory of Fehr and Schmidt believes that, as the effect of fair 
psychology, when people compare their own material interest with that of others, a side psychological effect will be created: jealousy will lead to negative utility when people's own material interest is lowered compared to that of others, and pride will lead to positive utility when people's own material interest is higher than that of others) and built a multistaged principal-agent model based on adapted fairness preference. The results show that if EN have fairness preference, the incentive degree to them from VC will increase. Thus the VC will higher the aggregation of previous efforts and current effort (which is uncertain), the risk cost is increased, and the incentive and total agent cost will be lowered.

The following passage goes as fellows. Section 2 shows the fundamental suggestion and model. As a benchmark, Section 3 builds the multistaged principle-agent model without basing on fairness preference under the condition of information asymmetry. Section 4 builds the multistaged model based on the adapted fairness preference theory under the condition of information asymmetry. Section 5 adopts the method of simulation to solve the equilibrium solution to the model (the optimal incentive contract). Based on the simulation computing, Section 6 is static analysis of two models; Section 7 concludes the whole paper and gives directions to the relevant future research aspects.

\section{Model Assumptions and Model Building}

2.1. Model Assumptions. If $\mathrm{VC}$ has unified their investment intentions, the VC will provide outside capital $I(I \geq 0)$. Assume that the VC is risk neutral and has the corresponding risk sustain ability to the possible profit and that EN is risk adverse. VC and EN are entirely rational (but in Section 3, we assume that EN is bounded rational behavior). The goal of EN's decision is to maximize the profits' utility, and the VC's decision target is to maximize the utility of their profits.

In different stages, EN puts out different efforts and denotes the effort he puts out in stage $k$ as $e_{k}, k=1,2, \ldots$. Assume that the cost of efforts can be denoted as the monetary cost $c\left(e_{k}\right)$. To simplify, assume that the EN's effort utility function is $c\left(e_{k}\right)=(1 / 2) b e_{k}^{2}, b>0$. The effort cost of EN increases with the effort, and the accelerating speed is increasing. This means that the function satisfies $c^{\prime}\left(e_{k}\right)>0$ and $c^{\prime \prime}\left(e_{k}\right)>0$.

Without losing generality, we consider the first and second stages (to simplify our model, this paper focuses on two stages, which is in response to the assumption of certain researchers, among which are Dahiya and Ray in 2012 and Wu and Lai in 2013), $k=1,2$. In the first stage, the VC's decision variables include the fixed compensation $\alpha$, which is to the entrepreneur, the first stage incentive coefficient is (which can also be considered as equities) $\beta_{1}\left(0 \leq \beta_{1} \leq 1\right)$, and the second stage incentive coefficient is $\beta_{2}\left(0 \leq \beta_{2} \leq 1\right)$. We refer to $\left(\alpha, \beta_{1}, \beta_{2}\right)$ as investment incentive contract. This paper discusses multistaged models, so we need to consider the time value of the profits. Therefore we assume that the VC's discount factor is $\delta_{C}$, and the discount factor of EN is $\delta_{E}$. Considering that the VC cares more about the future valuation of venture projects, $\delta_{C}$ and $\delta_{E}$ satisfy $0 \leq \delta_{E} \leq \delta_{C} \leq 1$.

The gaming order and decision variables are in Figure 1.
2.2. Model Constructions. The profit of venture project is decided by the EN's efforts $e_{1}$ and $e_{2}$, his capability $\theta$, and the external random variable $\varepsilon_{i}(i=1,2)$. The random variables $\varepsilon_{1}$ and $\varepsilon_{2}$ are independent, and $E\left(\varepsilon_{i}\right)=0$ and $D\left(\varepsilon_{i}\right)=\sigma_{i}$. Denote the venture project's revenue in each stage as $X_{i}$; then

$$
X_{i}=\theta+e_{i}+\varepsilon_{i}
$$

Denote the EN's profits as $\pi$, which equals the fixed compensation $\alpha$ plus each stage's revenue. Therefore, the profit of the $\mathrm{EN}$ is

$$
\pi=\pi_{1}+\delta_{E} \pi_{2}-c\left(e_{1}\right)-c\left(e_{2}\right)
$$

Since $\pi_{1}=\alpha+\beta_{1} X_{1}$ and $\pi_{2}=\beta_{2} X_{2}$, we have a further representation of his profit:

$$
\begin{aligned}
\pi= & \alpha+\beta_{1}\left(\theta+e_{1}+\varepsilon_{1}\right)+\delta_{E} \beta_{2}\left(\theta+e_{2}+\varepsilon_{2}\right)-\frac{1}{2} b e_{1}^{2} \\
& -\frac{1}{2} b e_{2}^{2} .
\end{aligned}
$$

Since we have assumed that the EN is risk adverse, his certainty equivalent income is $\mathrm{CE}$, according to the literature [25]. (Literature [25] has detailed derivation process, if the reader needs to be obtained from the author.)

$$
\begin{aligned}
\mathrm{CE}= & \alpha+\beta_{1}\left(\theta+e_{1}\right)+\delta_{E} \beta_{2}\left(\theta+e_{2}\right)-\frac{1}{2} b e_{1}^{2}-\frac{1}{2} b e_{2}^{2} \\
& -\frac{1}{2} \rho\left(\beta_{1}^{2} \sigma_{1}^{2}+\delta_{E}^{2} \beta_{2}^{2} \sigma_{2}^{2}\right) .
\end{aligned}
$$

Among that, $\rho>0$ represents the level of risk avoiding, and $(1 / 2) \rho\left(\beta_{1}^{2} \sigma_{1}^{2}+\delta_{E}^{2} \beta_{2}^{2} \sigma_{2}^{2}\right)$ represents the risk premium.

The profit of $\mathrm{VC}$ is

$$
\Pi=-\alpha+\left(1-\beta_{1}\right) X_{1}+\delta_{C}\left(1-\beta_{2}\right) X_{2}-I .
$$

From now on we have the project's revenue representation and substitute it into the equation above and we have

$$
\begin{aligned}
\Pi= & -\alpha+\left(1-\beta_{1}\right)\left(\theta+e_{1}+\varepsilon_{1}\right) \\
& +\delta_{C}\left(1-\beta_{2}\right)\left(\theta+e_{2}+\varepsilon_{2}\right)-I .
\end{aligned}
$$

Now that the VC is risk neutral, his expected utility is equal to his expected profit:

$$
\begin{aligned}
E \Pi= & -\alpha+\left(1-\beta_{1}\right)\left(\theta+e_{1}\right)+\delta_{C}\left(1-\beta_{2}\right)\left(\theta+e_{2}\right) \\
& -I .
\end{aligned}
$$

The VC will choose the investment incentive contract $\left(\alpha, \beta_{1}, \beta_{2}\right)$ to maximize his expected utility:

$$
\begin{aligned}
\max _{\alpha, \beta_{1}, \beta_{2}} & -\alpha+\left(1-\beta_{1}\right)\left(\theta+e_{1}\right)+\delta_{C}\left(1-\beta_{2}\right)\left(\theta+e_{2}\right) \\
& -I .
\end{aligned}
$$




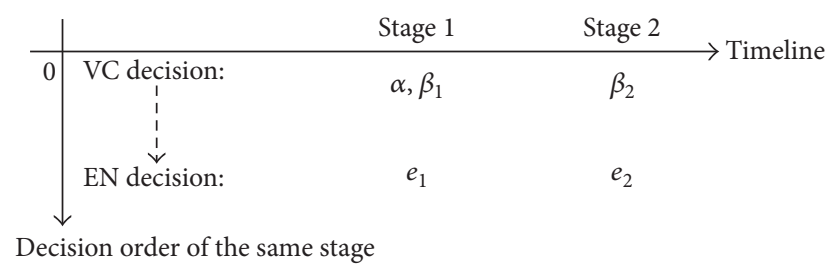

FIgURE 1: The game sequence and decision variables of VC and EN.

Remark 1. An illustration to the discount factors of VC and EN: since this paper is focused on a multistaged investment issue, profits in different terms should be discounted back to the first term. Therefore, there are two discount factor in this paper, one is the VC's discount factor $\delta_{C}$, while the other is the EN's discount factor $\delta_{E}$. The VC is more focused on the future profit. Therefore it is feasible to assume that $\delta_{C} \geq \delta_{E}$. To ensure that the incentive coefficient is between 0 and 1 , $\delta_{C}, \delta_{E}$ must satisfy $b \delta_{C} /\left(\delta_{C}+b\right) \leq \delta_{E} \leq \delta_{C}$.

\section{Multistage Principal-Agent Model without Fairness Preference under Information Asymmetry}

The decision of EN whether to accept the investment incentive contract offered by the VC is affected by the EN's potential opportunity cost. The EN will accept the contract only when his expected utility by accepting it is no less than the expected utility by rejecting it (which is called reserve utility $w_{0}$ ), also known as the individual rational constraint (IR). That is as follows:

$$
\begin{aligned}
\text { (IR) } & \alpha+\beta_{1}\left(\theta+e_{1}\right)+\delta_{E} \beta_{2}\left(\theta+e_{2}\right)-\frac{1}{2} b e_{1}^{2}-\frac{1}{2} b e_{2}^{2} \\
& -\frac{1}{2} \rho\left(\beta_{1}^{2} \sigma_{1}^{2}+\delta_{E}^{2} \beta_{2}^{2} \sigma_{2}^{2}\right) \geq w_{0} .
\end{aligned}
$$

The VC hopes to pay as less as possible. Finally, it will equal the reserve utility $w_{0}$. So the individual rationality (IR) condition of EN can be changed to

$$
\begin{aligned}
\text { (IR) } & \alpha+\beta_{1}\left(\theta+e_{1}\right)+\delta_{E} \beta_{2}\left(\theta+e_{2}\right)-\frac{1}{2} b e_{1}^{2}-\frac{1}{2} b e_{2}^{2} \\
& -\frac{1}{2} \rho\left(\beta_{1}^{2} \sigma_{1}^{2}+\delta_{E}^{2} \beta_{2}^{2} \sigma_{2}^{2}\right)=w_{0} .
\end{aligned}
$$

If the EN accepts this incentive contract, he will absolutely input efforts $e_{1}, e_{2}$ to maximize his utility. This is the incentive compatibility (IC) condition.

$$
\text { (IC) } \begin{aligned}
\left(e_{1}^{*}, e_{2}^{*}\right) \in & \arg \max _{e_{1}, e_{2}} \alpha+\beta_{1}\left(\theta+e_{1}\right) \\
& +\delta_{E} \beta_{2}\left(\theta+e_{2}\right)-\frac{1}{2} b e_{1}^{2}-\frac{1}{2} b e_{2}^{2} \\
& -\frac{1}{2} \rho\left(\beta_{1}^{2} \sigma_{1}^{2}+\delta_{E}^{2} \beta_{2}^{2} \sigma_{2}^{2}\right) .
\end{aligned}
$$

Its first-order condition is $e_{1}^{*}=(1 / b) \beta_{1}$ and $e_{2}^{*}=(1 /$ b) $\delta_{E} \beta_{2}$. So the incentive compatibility (IC) condition can be changed to

$$
\text { (IC) } \begin{aligned}
e_{1}^{*} & =\frac{1}{b} \beta_{1}, \\
e_{2}^{*} & =\frac{1}{b} \delta_{E} \beta_{2} .
\end{aligned}
$$

So the principal-agent model (I) is

$$
\begin{array}{ll}
\max _{\alpha, \beta_{1}, \beta_{2}} \quad-\alpha+\left(1-\beta_{1}\right)\left(\theta+e_{1}\right)+\delta_{C}\left(1-\beta_{2}\right)\left(\theta+e_{2}\right) \\
\text { st: } \quad \text { (IC) } e_{1}^{*}=\frac{1}{b} \beta_{1}, \\
e_{2}^{*}=\frac{1}{b} \delta_{E} \beta_{2} . \\
\text { (IR) } \alpha+\beta_{1}\left(\theta+e_{1}\right)+\delta_{E} \beta_{2}\left(\theta+e_{2}\right)-\frac{1}{2} b e_{1}^{2} \\
\quad-\frac{1}{2} b e_{2}^{2}-\frac{1}{2} \rho\left(\beta_{1}^{2} \sigma_{1}^{2}+\delta_{E}^{2} \beta_{2}^{2} \sigma_{2}^{2}\right)=w_{0} .
\end{array}
$$

Substituting the individual rationality (IR) condition and the incentive compatibility (IC) condition into expected profit function of the VC yields

$$
\begin{aligned}
\max _{\beta_{1}, \beta_{2}} & \left(\theta+\frac{1}{b} \beta_{1}\right) \\
& +\left(\delta_{E} \beta_{2}+\delta_{C}-\delta_{C} \beta_{2}\right)\left(\theta+\frac{1}{b} \delta_{E} \beta_{2}\right)-\frac{1}{2 b} \beta_{1}^{2} \\
& -\frac{1}{2 b} \delta_{E}^{2} \beta_{2}^{2}-\frac{1}{2} \rho\left(\beta_{1}^{2} \sigma_{1}^{2}+\delta_{E}^{2} \beta_{2}^{2} \sigma_{2}^{2}\right)-w_{0}-I .
\end{aligned}
$$

The first-order for $\beta_{1}$ and $\beta_{2}$ is, respectively,

$$
\begin{aligned}
& \beta_{1}^{*}=\frac{1}{1+b \rho \sigma_{1}^{2}}, \\
& \beta_{2}^{*}=\frac{\delta_{C} \delta_{E}-\left(\delta_{C}-\delta_{E}\right) b \theta}{2 \delta_{C} \delta_{E}-\delta_{E}^{2}+b \rho \delta_{E}^{2} \sigma_{2}^{2}}, \quad\left(\frac{b \delta_{C}}{\delta_{C}+b} \leq \delta_{E} \leq \delta_{C}\right) .
\end{aligned}
$$

Remark 2. Explanation of $\beta_{1}^{*}$ and $\beta_{2}^{*}: \beta_{1}^{*}$ and $\beta_{2}^{*}$ are revenuesharing incentive coefficients, which should be between 0 and 1. Apparently, $0 \leq \beta_{1}^{*} \leq 1$ is true. And if $2 \delta_{C} \delta_{E}-\delta_{E}^{2}$ is not less than $\delta_{C} \delta_{E}-\left(\delta_{C}-\delta_{E}\right) b \theta, 0 \leq \beta_{2}^{*} \leq 1$ is true. Actually, because 
$\delta_{C} \geq \delta_{E}$ is true for the discount coefficients (see Remark 1), $2 \delta_{C} \delta_{E}-\delta_{E}^{2}-\delta_{C} \delta_{E}+\left(\delta_{C}-\delta_{E}\right) b \theta=\left(\delta_{C}-\delta_{E}\right)\left(\delta_{E}+b \theta\right) \geq 0$ is true.

Substituting optimal incentive coefficient into the incentive compatibility (IC) condition yields the efforts of the EN:

$$
\begin{aligned}
& e_{1}^{*}=\frac{1}{b\left(1+b \rho \sigma_{1}^{2}\right)}, \\
& e_{2}^{*}=\frac{\delta_{C} \delta_{E}^{2}-\delta_{E}\left(\delta_{C}-\delta_{E}\right) b \theta}{2 \delta_{C} \delta_{E}-\delta_{E}^{2}+b \rho \delta_{E}^{2} \sigma_{2}^{2}} .
\end{aligned}
$$

\section{Multistage Principal-Agent Model under Information Asymmetry Based on Fairness Preference}

One assumption of the multistage principal-agent model in Section 2 is as follows: VC and EN are completely rational. In Section 1, we review in detail the meaning and definition of fairness preference. In this section, we implant fairness preference theory into a multistage principal-agent model. Let us first introduce F-S model [26]. Fehr and Schmidt define the fairness as self-centered inequity aversion. They assume that participants care about not only their own benefits, but also the difference between theirs and those of others. In addition, the evenness of income can affect the people's utility level. Given the allocation vector $x=\left(x_{1}, x_{2}, \ldots, x_{n}\right)$, the utility function of participant $i$ is [26]

$$
\begin{aligned}
U_{i}(x)= & x_{i}-u_{i} \frac{1}{n-1} \sum_{j \neq i} \max \left\{x_{j}-x_{i}, 0\right\} \\
& -v_{i} \frac{1}{n-1} \sum_{j \neq i} \max \left\{x_{i}-x_{j}, 0\right\} .
\end{aligned}
$$

The second item of the function right above measures the loss of utility caused by the inequity in inferior position. The third item measures the loss of utility caused by the inequity in superiority position. We assume that $u_{i} \geq v_{i}$, which means that participants in inferior position feel more inequity. We also assume that $0 \leq v_{i} \leq 1 . v_{i} \geq 0$ implies that we eliminate those who enjoy being better than others, such as those pursuing social status and those with jealousy mentality. $v_{i} \geq 1$ is not consistent with normal logic. The utility of participant $i$ is a function of $x_{j}$, when $x_{i}$ is given. The conclusion of this model is consistent with the results of a great number of experiments. Meanwhile, the equilibrium of this model is unique, which makes it more convenient.

The principal-agent model based on fairness preference in our paper is mostly based on the multistage model. And we need to note that the equity will not only affect the behavior in current period but also affect the behavior in next stage. Our paper builds the model to analyze it based on such truth. In the relationship of venture capital, VC as principal has rights to distribute profits of the venture project, and the $\mathrm{EN}$ as an agent in a subordinate position is vulnerable to unfair treatment. So we only assume that the EN has fairness preference. In reality, the profit of EN is always less than the VC, implying $\widetilde{\Pi}_{1}-\widetilde{\pi}_{1}>0$. So EN is always only with jealousy preference and without sympathy preference. Fehr and Schmidt's research shows that psychological jealousy is stronger than psychological sympathy [20]. The existing research shows that the decision-makers pay more attention to profits less than others, and they do not care when they have more profits than others $[26,27]$. The experiment from the reference $[28,29]$ also shows that, in general, people show little enthusiasm when they have more profits than others. So suppose that $v=0$.

According to the logic in function (17), we improve the F$S$ model of Fehr and Schmidt [20]. The effort $\tilde{e}_{2}$ in the second stage is the function of $u \max \left[E\left(\widetilde{\Pi}_{1}-\widetilde{\pi}_{1}\right), 0\right]$, denoted as $\widetilde{e}_{2}[\cdot]$, where $E\left(\widetilde{\Pi}_{1}-\widetilde{\pi}_{1}\right)$ is expectation. The utility function of the EN can be changed to

$$
U=\tilde{\pi}_{1}+\delta \tilde{\pi}_{2}-c\left(\tilde{e}_{1}\right)-c\left(\tilde{e}_{2}[\cdot]\right),
$$

where

$$
\begin{aligned}
& \widetilde{\pi}_{1}=\widetilde{\alpha}+\widetilde{\beta}_{1} \widetilde{X}_{1}, \\
& \widetilde{\Pi}_{1}=\left(1-\widetilde{\beta}_{1}\right) \widetilde{X}_{1}-\widetilde{\alpha}, \\
& \widetilde{\Pi}_{2}=\left(1-\widetilde{\beta}_{2}\right) \widetilde{X}_{2} .
\end{aligned}
$$

Effort level in the second stage is affected by the result of the first result, so we think that there are two trains of thought to determine the relationship between $\widetilde{e}_{2}, E\left(\widetilde{\Pi}_{1}-\widetilde{\pi}_{1}\right)$, and $\tilde{e}_{2}[\cdot]$.

The first one is to get relevant data by simulated experiment to fit the relationship between $\widetilde{e}_{2}$ and $E\left(\widetilde{\Pi}_{1}-\widetilde{\pi}_{1}\right)$.

The second one is to set the mathematical relationship between them.

Our paper is using the second one. We assume that the effort level $\widetilde{e}_{2}$ in the second stage is affected by $E\left(\widetilde{\Pi}_{1}-\widetilde{\pi}_{1}\right)$. The smaller $E\left(\widetilde{\Pi}_{1}-\widetilde{\pi}_{1}\right)$ is, the larger $\widetilde{e}_{2}$ is and vice versa. And

$$
\begin{gathered}
\frac{\partial \widetilde{e}_{2}}{\partial\left(E\left(\widetilde{\Pi}_{1}-\widetilde{\pi}_{1}\right)\right)} \leq 0 \\
\frac{\partial^{2} \widetilde{e}_{2}}{\partial\left(E\left(\widetilde{\Pi}_{1}-\widetilde{\pi}_{1}\right)\right)^{2}}>0
\end{gathered}
$$

are satisfied. Figure 2 shows the relationship.

We assume that $\widetilde{e}_{2}$ can be divided into two parts: $\widetilde{e}_{21}$ and $\widetilde{e}_{22} \cdot \widetilde{e}_{21}$ is the effort not affected by fairness preference, and $\widetilde{e}_{22}$ is the effort which can be affected by fairness preference. $E\left(\widetilde{\Pi}_{1}-\widetilde{\pi}_{1}\right)$ is not equal to zero because the profits of VC and EN are different, so $\widetilde{e}_{2}$ will not tend to infinity. So we assume that the effort level of $\mathrm{EN}$ in the second period has a revers relationship with $E\left(\widetilde{\Pi}_{1}-\widetilde{\pi}_{1}\right)$. Such a relationship can be tested by simulation. So we assume that

$$
\tilde{e}_{2}[\cdot]=\frac{\tilde{e}_{21}+\tilde{e}_{22}}{E\left(\widetilde{\Pi}_{1}-\tilde{\pi}_{1}\right)}
$$




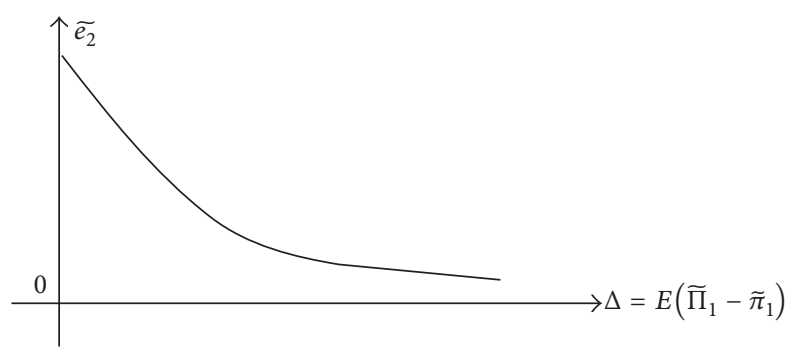

Figure 2: The relation between $\widetilde{e}_{2}$ and $\Delta=\widetilde{\Pi}_{1}-\widetilde{\pi}_{1}$.

We also assume that the profit under fairness preference is $\widetilde{X}_{i}, \widetilde{X}_{i}=\theta+\widetilde{e}_{i}+\widetilde{\varepsilon}_{i}$, where $E\left(\widetilde{\varepsilon}_{i}\right)=0$ and $D\left(\widetilde{\varepsilon}_{i}\right)=\sigma_{i}^{2}$. So the profit of EN under fairness preference is as follows:

$$
\tilde{\pi}=\tilde{\alpha}+\widetilde{\beta}_{1} \widetilde{X}_{1}+\delta_{E} \widetilde{\beta}_{2} \widetilde{X}_{2}-c\left(\widetilde{e}_{1}\right)-c\left(\widetilde{e}_{2}[\cdot]\right) .
$$

Substituting (18) and (19) into (17) yields

$$
\begin{aligned}
\widetilde{U} & =\widetilde{\alpha}+\widetilde{\beta}_{1}\left(\theta+\widetilde{e}_{1}+\widetilde{\varepsilon}_{1}\right) \\
& +\delta_{E} \widetilde{\beta}_{2}\left\{\theta+\frac{\widetilde{e}_{21}+\widetilde{e}_{22}}{u\left[\theta+\widetilde{e}_{1}-2 \widetilde{\alpha}-2 \widetilde{\beta}_{1}\left(\theta+\widetilde{e}_{1}\right)\right]}+\widetilde{\varepsilon}_{2}\right\} \\
& -\frac{1}{2} b\left(\widetilde{e}_{1}\right)^{2} \\
& -\frac{1}{2} b\left\{\frac{\widetilde{e}_{21}+\widetilde{e}_{22}}{u\left[\theta+\widetilde{e}_{1}-2 \widetilde{\alpha}-2 \widetilde{\beta}_{1}\left(\theta+\widetilde{e}_{1}\right)\right]}\right\}^{2}
\end{aligned}
$$

According to Sections 2 and 3, determinately equivalent utility is

$$
\begin{aligned}
\widetilde{\mathrm{CE}}_{U} & \\
= & \widetilde{\alpha}+\widetilde{\beta}_{1}\left(\theta+\widetilde{e}_{1}\right) \\
& +\delta_{E} \widetilde{\beta}_{2}\left\{\theta+\frac{\widetilde{e}_{21}+\widetilde{e}_{22}}{u\left[\theta+\widetilde{e}_{1}-2 \widetilde{\alpha}-2 \widetilde{\beta}_{1}\left(\theta+\widetilde{e}_{1}\right)\right]}\right\} \\
& -\frac{1}{2} b\left(\widetilde{e}_{1}\right)^{2} \\
& -\frac{1}{2} b\left\{\frac{\tilde{e}_{21}+\widetilde{e}_{22}}{u\left[\theta+\widetilde{e}_{1}-2 \widetilde{\alpha}-2 \widetilde{\beta}_{1}\left(\theta+\widetilde{e}_{1}\right)\right]}\right\}^{2} \\
& -\frac{1}{2} \rho \widetilde{\beta}_{1}^{2} \sigma_{1}^{2}-\frac{1}{2} \rho \delta_{E}^{2} \widetilde{\beta}_{2}^{2} \sigma_{2}^{2} .
\end{aligned}
$$

Among them $\tilde{e}_{21}$ is the optimal effort level without fairness preference, so we need to solve the optimal

$$
\widetilde{e}_{21}=e_{2}^{*}=\frac{\delta_{C} \delta_{E}^{2}-\delta_{E}\left(\delta_{C}-\delta_{E}\right) b \theta}{2 \delta_{C} \delta_{E}-\delta_{E}^{2}+b \rho \delta_{E}^{2} \sigma_{2}^{2}} .
$$

The first-order condition of (21) implies that EN chooses the effort levels $\widetilde{e}_{1}$ and $\widetilde{e}_{21}$ to maximize his determinately equivalent utility:

$$
\begin{aligned}
& \text { (IC1) } \tilde{\beta}_{1}+\left\{\frac{\tilde{e}_{21}+\tilde{e}_{22}}{u\left[\theta+\widetilde{e}_{1}-2 \widetilde{\alpha}-2 \widetilde{\beta}_{1}\left(\theta+\widetilde{e}_{1}\right)\right]}\right. \\
& +b\left\{\frac{\left(\widetilde{e}_{21}+\widetilde{e}_{22}\right)^{2}}{u^{2}\left[\theta+\widetilde{e}_{1}-2 \widetilde{\alpha}-2 \widetilde{\beta}_{1}\left(\theta+\widetilde{e}_{1}\right)\right]^{3}}\right\}, \\
& \text { (IC2) } \delta_{E} \widetilde{\beta}_{2} u\left[\theta+\widetilde{e}_{1}-2 \widetilde{\alpha}-2 \widetilde{\beta}_{1}\left(\theta+\widetilde{e}_{1}\right)\right] \\
& -b\left(\widetilde{e}_{21}+\widetilde{e}_{22}\right) .
\end{aligned}
$$

Then we get the principal-agent model (III):

$$
\begin{aligned}
& \max _{\alpha, \beta_{1}, \beta_{2}}-\alpha+\left(1-\beta_{1}\right)\left(\theta+e_{1}\right)+\delta_{C}\left(1-\beta_{2}\right)\left(\theta+e_{2}\right)-I \\
& \text { st: } \quad \text { (IC1) } \widetilde{\beta}_{1}+\left\{\frac{\widetilde{e}_{21}+\widetilde{e}_{22}}{u\left[\theta+\widetilde{e}_{1}-2 \widetilde{\alpha}-2 \widetilde{\beta}_{1}\left(\theta+\widetilde{e}_{1}\right)\right]}\right\} \\
& -b \widetilde{e}_{1}+b\left\{\frac{\left(\widetilde{e}_{21}+\widetilde{e}_{22}\right)^{2}}{u^{2}\left[\theta+\widetilde{e}_{1}-2 \widetilde{\alpha}-2 \widetilde{\beta}_{1}\left(\theta+\widetilde{e}_{1}\right)\right]^{3}}\right\} \text {. } \\
& \text { (IC2) } \delta_{E} \widetilde{\beta}_{2} u\left[\theta+\widetilde{e}_{1}-2 \widetilde{\alpha}-2 \widetilde{\beta}_{1}\left(\theta+\widetilde{e}_{1}\right)\right] \\
& -b\left(\widetilde{e}_{21}+\widetilde{e}_{22}\right) \\
& \text { (IR) } \widetilde{\alpha}+\widetilde{\beta}_{1}\left(\theta+\widetilde{e}_{1}\right) \\
& +\delta_{E} \widetilde{\beta}_{2}\left\{\theta+\frac{\widetilde{e}_{21}+\widetilde{e}_{22}}{u\left[\theta+\widetilde{e}_{1}-2 \widetilde{\alpha}-2 \widetilde{\beta}_{1}\left(\theta+\widetilde{e}_{1}\right)\right]}\right\} \\
& -\frac{1}{2} b\left(\widetilde{e}_{1}\right)^{2} \\
& -\frac{1}{2} b\left\{\frac{\tilde{e}_{21}+\widetilde{e}_{22}}{u\left[\theta+\widetilde{e}_{1}-2 \widetilde{\alpha}-2 \widetilde{\beta}_{1}\left(\theta+\widetilde{e}_{1}\right)\right]}\right\}^{2} \\
& -\frac{1}{2} \rho \widetilde{\beta}_{1}^{2} \sigma_{1}^{2}-\frac{1}{2} \rho \delta_{E}^{2} \widetilde{\beta}_{2}^{2} \sigma_{2}^{2}=w_{0} \text {. }
\end{aligned}
$$

It is difficult to get the explicit solution of model (III) by mathematical method. However it is complicated, because we focus on venture investment management practice. In Section 5 we adopt the simulation to get numerical solution. 
TABLE 1: The values of the parameters $u$.

\begin{tabular}{llllllll}
\hline$u$ & 0.26000 & 0.49000 & 0.77000 & 0.65000 & 0.62000 & 0.31000 & 0.77000 \\
$u$ & 0.37000 & 0.13000 & 0.64000 & 0.36000 & 0.21000 & 0.12000 & 0.20000 \\
$u$ & 0.24000 & 0.89000 & 0.15000 & 0.38000 & 0.74000 & 0.75000 & 0.86000 \\
$u$ & 0.20000 & 0.56000 & 0.45000 & 0.92000 & 0.45000 & 0.43000 & 0.88000 \\
\hline
\end{tabular}

TABLE 2: The values of other parameters.

\begin{tabular}{llllllll}
\hline$b=1$ & $\delta_{C}=1$ & $\delta_{E}=0.6$ & $\theta=1$ & $\rho=1$ & $\sigma_{1}^{2}=1$ & $\sigma_{2}^{2}=1$ & $I=0$
\end{tabular}

Table 1 and the other parameters' values in Section 5 show $u$ 's value and Table 2 shows the simulation result.

\section{A Simulation of Multistaged Agency Problems Based on Fairness Preference under Asymmetric Information}

Considering its various parameters and its own complexity, we are facing great difficulty working out the analytical solution of model (III) in a direct approach, and, therefore, in this paper, we adopt a simulative algorithm. The multistaged agency model (III) belongs to the Stackelberg decision problem, and so far scholars have derived a series of algorithms accordingly $[30,31]$.

This paper focuses on the relationship of venture investment based on fairness preference, which is also regarded as a kind of bounded rationality. To seek for the multistaged agency model's equilibrium solution using the simulative algorithm, we assume that EN meets both the incentive compatibility constraint (IC) and the individual rationality constraint (IR).

The algorithm follows the process below.

Step 1. Initialize the numbers of parameters (see Tables 1 and 2) and take the first one for parameter $u$.

Step 2. Use Matlab programming to calculate the objective function value of the VC and the values of the optimal decision variables $\widetilde{e}_{1}, \widetilde{e}_{22}, \widetilde{\alpha}, \widetilde{\beta}_{1}, \widetilde{\beta}_{2}$ to meet the incentive compatibility constraints (IC1) and (IC2) and participation constraint (IR).

Step 3. Iterate Step 1 with the rest 27 value of parameter $u$ and thus attain all the optimal values for parameters $\tilde{e}_{1}, \widetilde{e}_{22}, \widetilde{\alpha}, \widetilde{\beta}_{1}$, and $\widetilde{\beta}_{2}$ and the desired function values for VC.

Step 4. Take the value of parameters $\widetilde{e}_{1}, \widetilde{e}_{22}, \widetilde{\alpha}, \widetilde{\beta}_{1}$, and $\widetilde{\beta}_{2}$ that make the maximum of all the 28 function values for VC. Such five parameters are composed of the optimal solution to this simulation.

Section 5 focuses on the influence of fairness preference on the decision of $\mathrm{VC}$ and EN. Therefore, when initializing the values for parameter $u$, we need to take its distribution character into account. Here we assume that it follows a uniform distribution between 0 and 1 (see Table 1 ).
For other parameters' values, see Table 2.

Via Matlab programming, we acquired the simulation results of the simplified simulation model (see Appendix), which are showed in Table 3.

We can therefore draw our first conclusion from the results exhibited in Table 2 .

Conclusion 1. Consider the venture investment relationship during which the EN's efforts are multistaged. If EN is featured with the fairness preference, under the information asymmetry condition, the optimal incentive value would be $\widetilde{\beta}_{1}{ }^{*}=0.20676$ and $\widetilde{\beta}_{2}{ }^{*}=0.00338$, the optimal fixed income $\widetilde{\alpha}^{*}=0.25534$, and the optimal efforts of EN $\widetilde{e}_{1}{ }^{*}=0.20675$ and $\widetilde{2}_{1}{ }^{*}=\widetilde{e}_{21}{ }^{*}+\widetilde{e}_{22}{ }^{*}=1.035+0.00004=1.0354$. Thus the optimal utility for EN is 1.75138 and the actual income is 0.603931 .

Comment 1. Using varied fairness preferences in model III, we have obtained in Table 2 different optimal results. From the table we see that the optimal utility for VC (shown in the second column of Table 2) is 1.75138 and that the corresponding values of other parameters (line 18 in Table 3) work as the parameters' optimal values for the model.

Taking these specific optimal values into the following function (in model III) of EN's actual income,

$$
\begin{aligned}
\widetilde{\alpha} & \widetilde{\beta}_{1}\left(\theta+\widetilde{e}_{1}\right) \\
& +\delta_{E} \widetilde{\beta}_{2}\left\{\theta+\frac{\widetilde{e}_{21}+\widetilde{e}_{22}}{u\left[\theta+\widetilde{e}_{1}-2 \widetilde{\alpha}-2 \widetilde{\beta}_{1}\left(\theta+\widetilde{e}_{1}\right)\right]}\right\},
\end{aligned}
$$

we have the optimal actual income 0.57789 .

\section{A Static Analysis of Two Models}

In the previous section, we have constructed two models based on two dimensions: whether the information is symmetric and whether the EN possesses fairness preference. Thus, naturally, when comparing the two, we derive the following questions:

(1) What is the size relationship between, in different stages, the optimal incentive values $\left(\alpha, \beta_{1}, \beta_{2}\right)$ ?

(2) What is the size relationship between, in different stages, the optimal efforts $\left(e_{1}, e_{21}, e_{22}\right)$ ? 
TABLE 3: The simulation results of fairness preference model under asymmetric information.

\begin{tabular}{|c|c|c|c|c|c|c|c|}
\hline$u$ & $\widetilde{\Pi}^{*}$ & $\tilde{\pi}^{*}$ & $\widetilde{\alpha}^{*}$ & $\widetilde{\beta}_{1}{ }^{*}$ & $\widetilde{\beta}_{2}^{*}$ & $\widetilde{e}_{22}{ }^{*}$ & $\tilde{e}_{1}^{*}$ \\
\hline 0.26000 & 1.74957 & 0.587533 & 0.24874 & 0.22303 & 0.00476 & 0.00009 & 0.22300 \\
\hline 0.49000 & 1.74862 & 0.570845 & 0.25064 & 0.20916 & 0.00979 & 0.00039 & 0.20908 \\
\hline 0.77000 & 1.74978 & 0.499849 & 0.26573 & 0.17912 & 0.00548 & 0.00038 & 0.17911 \\
\hline 0.65000 & 1.74698 & 0.580546 & 0.24395 & 0.23079 & 0.00866 & 0.00039 & 0.23069 \\
\hline 0.62000 & 1.75041 & 0.532554 & 0.25552 & 0.20183 & 0.00630 & 0.00032 & 0.20180 \\
\hline 0.31000 & 1.74346 & 0.623317 & 0.26084 & 0.17400 & 0.01793 & 0.00054 & 0.17390 \\
\hline 0.77000 & 1.74249 & 0.616693 & 0.23761 & 0.23353 & 0.01809 & 0.00101 & 0.23311 \\
\hline 0.37000 & 1.74483 & 0.642611 & 0.24853 & 0.20141 & 0.01850 & 0.00060 & 0.20118 \\
\hline 0.13000 & 1.75107 & 0.603931 & 0.25445 & 0.20826 & 0.00392 & 0.00004 & 0.20825 \\
\hline 0.64000 & 1.74302 & 0.615378 & 0.24211 & 0.21224 & 0.02251 & 0.00123 & 0.21182 \\
\hline 0.36000 & 1.74964 & 0.559115 & 0.24786 & 0.22967 & 0.00267 & 0.00006 & 0.22966 \\
\hline 0.21000 & 1.74471 & 0.760409 & 0.24325 & 0.21975 & 0.01596 & 0.00026 & 0.21950 \\
\hline 0.12000 & 1.74527 & 0.856145 & 0.24198 & 0.23322 & 0.01076 & 0.00009 & 0.23306 \\
\hline 0.20000 & 1.74877 & 0.641317 & 0.25383 & 0.20139 & 0.00945 & 0.00016 & 0.20133 \\
\hline 0.24000 & 1.74005 & 0.631472 & 0.23821 & 0.26928 & 0.00212 & 0.00002 & 0.26927 \\
\hline 0.89000 & 1.74500 & 0.581904 & 0.24241 & 0.22013 & 0.01719 & 0.00121 & 0.21983 \\
\hline 0.15000 & 1.75138 & 0.57789 & 0.25534 & 0.20676 & 0.00338 & 0.00004 & 0.20675 \\
\hline 0.38000 & 1.75007 & 0.559916 & 0.24966 & 0.22136 & 0.00415 & 0.00011 & 0.22134 \\
\hline 0.74000 & 1.74331 & 0.610833 & 0.23924 & 0.22797 & 0.01822 & 0.00102 & 0.22759 \\
\hline 0.75000 & 1.74384 & 0.529962 & 0.26350 & 0.16927 & 0.01729 & 0.00128 & 0.16920 \\
\hline 0.86000 & 1.74688 & 0.566001 & 0.24334 & 0.24210 & 0.00415 & 0.00022 & 0.24207 \\
\hline 0.20000 & 1.74495 & 0.693312 & 0.25850 & 0.18139 & 0.01601 & 0.00030 & 0.18129 \\
\hline 0.56000 & 1.74107 & 0.647405 & 0.23627 & 0.25118 & 0.01212 & 0.00041 & 0.25090 \\
\hline 0.45000 & 1.74772 & 0.578245 & 0.25301 & 0.19920 & 0.01232 & 0.00048 & 0.19910 \\
\hline 0.92000 & 1.74841 & 0.554223 & 0.24685 & 0.22210 & 0.00848 & 0.00058 & 0.22202 \\
\hline 0.45000 & 1.74537 & 0.618082 & 0.24152 & 0.23793 & 0.00919 & 0.00027 & 0.23781 \\
\hline 0.43000 & 1.74562 & 0.580854 & 0.25783 & 0.18334 & 0.01564 & 0.00063 & 0.18324 \\
\hline 0.88000 & 1.74663 & 0.548652 & 0.25164 & 0.19706 & 0.01616 & 0.00126 & 0.19690 \\
\hline
\end{tabular}

(3) Compared with the regular models, is there a Pareto improvement towards the utility of $\mathrm{VC}$ and the actual income of EN when taking fair preference into account?

We will focus on these three questions in the following part.

In Section 2, we looked into the multistaged incentive system of EN without fairness preference and thus obtained its explicit solutions.

To compare the solutions above with the situation under fairness preference, we set parameters' values as in Sections 1 and 2 and reach the simulation results in Table 4.

From Conclusion 1 and Table 2, we reach Conclusion 2.

Conclusion 2. In a relationship of venture investment where EN makes multistaged efforts and where information is asymmetric, the incentive level will be higher, given that EN holds fairness preference, than those when EN holds no fairness preference. In other words $\beta_{1}^{*} \leq \widetilde{\beta}_{1}{ }^{*}$ and $\beta_{2}{ }^{*} \leq \widetilde{\beta}_{2}{ }^{*}$.

Comment 2. The significance of Conclusion 2 not only is important but also follows our intuition. First, if EN does not follow fairness preference, under information asymmetry,
TABLE 4: The simulation results of asymmetric information under no fairness preference.

\begin{tabular}{lccccc}
\hline$\beta_{1}^{*}$ & $\beta_{2}^{*}$ & $e_{1}^{*}$ & $e_{2}^{*}$ & $\Pi^{*}$ & $\pi^{*}$ \\
\hline 0.2000 & 0.0294 & 0.2000 & 0.0416 & 1.7083 & 0.495 \\
\hline
\end{tabular}

the incentive contract follows the solution for classic agency problem and the incentive level will be lower than that when being under fairness preference. The reason is that VC determines this optimal incentive contract with complete rationality, which means that when EN's utility is maximized, VC designs the contract based on maximizing its own utility. Therefore, there is no possibility for VC to share some benefits to EN.

Second, if EN follows fairness preference, under information asymmetry EN might have a sense of circumventing inequality. Taking this into account, with complete rationality VC will raise the incentive level towards EN. Such raise can both eliminate EN's sense of inequality circumvention and stimulate EN's putting more effort as return.

Practical Suggestion 1. Fairness preference, in a relationship of venture investment, is the key factor to a decision-maker: EN 
will put much attention towards the distribution of benefits. VC cannot write down every possible situation into the contract when information is asymmetric; thus EN will make every effort to obtain more benefit beyond the contract (such as focusing only on projects that benefit himself). Therefore, $\mathrm{VC}$ needs to give a greater incentive to EN. Compared with the condition under complete rationality, VC raising the level of incentives shows that it is proactively sharing some of his own benefit to the EN. According to the theory of fairness preference in behavior economy, VC is actually showing kindness to EN, and, accordingly, the EN will raise its efforts as return (shown in Conclusions 3 and 4). Now that the cake becomes larger, both the EN and the VC will share a larger piece from this improvement. Hence, when designing the contract, VC is suggested to make necessary sacrifices to show its kindness (e.g., to offer more benefit or to provide some useful training and suggestion towards EN). Although those practices will surely lead to increased cost in the short-run, in the long term, it will function as a wise decision.

From Conclusion 1 and Table 2, we also reach Conclusion 3.

Conclusion 3. In a relationship of venture investment where EN makes multistaged efforts and where information is asymmetric, in both stages the effort levels that EN with fairness preference makes will be higher than those when EN is without fairness preference. In other words $e_{1}^{*} \leq \widetilde{e}_{1}{ }^{*}$, and $e_{2}^{*} \leq \widetilde{e}_{2}^{*}$.

Comment 3. From the conclusion above we can deduce that there exists a long-run relationship between VC and EN. But to be succinct, in this paper we introduce a two-stage model. Conclusion 3 shows that if EN follows fairness preference, under information asymmetry it will make efforts higher than those when being without fairness preference.

Practical Suggestion 2. Once having infused venture capital, VC and EN form a long-run cooperation; hence, a staged incentive is beneficial to VC. To be treated fairly in the following stages, EN with fairness preference will make more efforts in the initial stages. Thus at this point VC ought to pay careful attention to the factors that EN really cares about. The higher the VC's incentive levels are, the more the efforts will EN make for a better result of the venture project. On the surface, the success of a venture project will directly result from EN's effort level, but when taking the issue as a whole, it will indirectly result from VC's higher incentives.

From Conclusion 1 and Table 3, we reach Conclusions 4 and 5 .

Conclusion 4. In a relationship of venture investment where EN makes multistaged efforts and where information is asymmetric, the total actual income for EN with fairness preference is higher than that for EN without fairness preference.

This conclusion shows that the EN's fairness preference will lead to a Pareto improvement (in the form of an increase in the actual income). This is mostly due to EN's trying to circumvent the possible inequality: more efforts will be put on the venture project, the project's output will be improved, and EN's total actual income will therefore be raised.
Comment 4. In Conclusion 4, we take EN's actual income as its utility. This is simply because in the agency problem model the individual rational constraint is tight and EN's utility is equal to the reservation utility $w_{0}$. Therefore, a discussion of actual income is of more practical meanings.

Conclusion 5. In a relationship of venture investment where EN makes multistaged efforts and where information is asymmetric, the VC could obtain higher utility when EN is with fairness preference than when EN is without fairness preference.

Practical Suggestion 3. In a relationship of venture investment where EN might have a sense of circumventing inequality, $\mathrm{VC}$, as the principal, should take the EN's fear of inequality into consideration. VC should realize that the contract designed under complete rationality is not its optimal choice and that its necessary benefit sacrifices for EN will result in EN's higher efforts as a do-good return. Hence, the venture project's return will increase, and so will the VC's profit. Such win-win contracts are current in corporate of Japan and Korea: they are willing to share their welfare with their partners and, in return, their partners will do good to these companies $[32,33]$. Therefore, in a relationship of a venture investment, it is of great importance for VC to consider EN's fairness preference and form a shared contract, for this will determine VC's concern towards EN's focus and will make a win-win situation. Different from the one under complete rationality, with the help of a share contract, a more harmonious and profitable cooperation will be obtained. Also, in such a situation, both the VC and the EN will experience a Pareto improvement in their outcome, whether the information is symmetric.

\section{Conclusive Remarks}

This paper qualifies the relationship between VC and EN with such features as interactive and long term. VC provides funding to startup ventures with the purpose of capital appreciation, hoping the initial investment is getting recovered as soon as possible and $\mathrm{EN}$ is sparing no effort to operate the project. However, the efforts EN makes and the management ability it possesses are all EN's private information, which will lead to information asymmetry between VC and EN. Therefore, realizing the multistaged, changeful characters of EN's effort, we have modified the classic model for principalagency problem and have regarded EN's effort value as a dynamic parameter. And to simplify the model, we assume that there are only two stages.

Further, to make it more practical and closer to the real world, we introduce into the model the fairness preference. The modified model with fairness preference differs from existing models in two aspects as follows. First, when evaluating the utilities of EN (the agent) and VC (the principal), we use the second stage's result as the comparable factor. This is because the result of the first stage is unpredictable and therefore cannot be compared. In other words, the result of the first stage would not affect the EN's efforts in the first stage but only the efforts for the second stage. Second, we 
classify the efforts for the second stage into two kinds. One only considers the effort from EN without considering its fairness preference, and another takes into consideration the excessive effort from a fairness-preferred EN.

However, the model becomes too complex to solve once EN follows fairness preference. We therefore adopt an algorithm of simulation to find out the optimal equilibriums under different levels of fairness preference and the values of discount factors. Thus, by constructing and analyzing the two models (one without fairness preference and another with fairness preference, both under asymmetric information), we draw the following conclusions.

First, in a relationship of venture investment where EN makes multistaged efforts and where information is asymmetric, the incentive level will be higher, given that EN holds fairness preference, than those when EN holds no fairness preference.

Second, in a relationship of venture investment where EN makes multistaged efforts and where information is asymmetric, in both stages the effort levels that EN with fairness preference makes will be higher than those when EN is without fairness preference.

Third, in a relationship of venture investment where EN makes multistaged efforts and where information is asymmetric, the total actual income for EN with fairness preference is higher than that for EN without fairness preference.

Fourth, in a relationship of venture investment where EN makes multistaged efforts and where information is asymmetric, the VC could obtain higher utility when EN is with fairness preference than when $\mathrm{EN}$ is without fairness preference.
Fifth, in a relationship of venture investment where EN might have a sense of circumventing inequality, VC, as the principal, should take the EN's fear of inequality into consideration. VC should realize that the contract designed under complete rationality is not its optimal choice and that its necessary benefit sacrifices for EN will result in EN's higher efforts as a do-good return. Hence, the venture project's return will increase, and so will the VC's profit.

However, there are other problems that need to be further studied.

First, how will the EN's fairness preference affect the principal-agency relationship in general? Would VC rather prefer EN with weaker fairness preference (a weaker tendency of envy) or one with stronger fairness preference (a stronger tendency of envy)?

Second, what is the relationship between EN's fairness preference and its degree of risk aversion? Will EN with stronger fairness preference choose to bear higher risk?

Third, in this paper we simplify the model into a two-stage one. To make it more practical and closer to the real world, we should instead consider infinite-staged model, which might become more sophisticated when building it and working out its result.

However, these issues mentioned above are what we will study in the future.

\section{Appendix}

\section{Model Simplification and Consolidation}

The parameters are brought into the original model to get the following model:

$$
\begin{aligned}
& \max _{\tilde{\alpha}, \widetilde{\beta}_{1}, \widetilde{\beta}_{2}}-\widetilde{\alpha}+\left(1-\widetilde{\beta}_{1}\right)\left(1+\widetilde{e}_{1}\right)+\left(1-\widetilde{\beta}_{2}\right)\left(1.053+\widetilde{e}_{22}\right) \\
& \text { st: } \quad(\mathrm{IC} 1) u^{2} \widetilde{\beta}_{1}\left[\left(1-2 \widetilde{\beta}_{1}\right)\left(1+\widetilde{e}_{1}\right)-2 \widetilde{\alpha}\right]^{3}+0.6 u\left(1.053+\widetilde{e}_{22}\right) \widetilde{\beta}_{2}\left(1-2 \widetilde{\beta}_{1}\right)\left[\left(1-2 \widetilde{\beta}_{1}\right)\left(1+\widetilde{e}_{1}\right)-2 \widetilde{\alpha}\right] \\
& -u^{2} \widetilde{e}_{1}\left[\left(1-2 \widetilde{\beta}_{1}\right)\left(1+\widetilde{e}_{1}\right)-2 \widetilde{\alpha}\right]^{3}+\left(1.053+\tilde{e}_{22}\right)^{2} \\
& \text { (IC2) } 0.6 \widetilde{\beta}_{2} u\left[\left(1-2 \widetilde{\beta}_{1}\right)\left(1+\widetilde{e}_{1}\right)-2 \widetilde{\alpha}\right]-\left(1.053+\widetilde{e}_{22}\right) \\
& \text { (IR) } 2 u\left[\widetilde{\alpha}+\widetilde{\beta}_{1}\left(1+\widetilde{e}_{1}\right)\right]\left[\left(1-2 \widetilde{\beta}_{1}\right)\left(1+\widetilde{e}_{1}\right)-2 \widetilde{\alpha}\right] \\
& +1.2 \widetilde{\beta}_{2} u\left[\left(1-2 \tilde{\beta}_{1}\right)\left(1+\tilde{e}_{1}\right)-2 \tilde{\alpha}\right]\left\{0.053+u\left[\left(1-2 \tilde{\beta}_{1}\right)\left(1+\tilde{e}_{1}\right)-2 \widetilde{\alpha}\right]\right\}-\tilde{e}_{1}^{2} u\left[\left(1-2 \tilde{\beta}_{1}\right)\left(1+\tilde{e}_{1}\right)-2 \widetilde{\alpha}\right] \\
& -0.0028-4 \widetilde{\beta}_{1}^{2} u\left[\left(1-2 \widetilde{\beta}_{1}\right)\left(1+\widetilde{e}_{1}\right)-2 \widetilde{\alpha}\right]-1.44 \widetilde{\beta}_{2}^{2} u\left[\left(1-2 \widetilde{\beta}_{1}\right)\left(1+\widetilde{e}_{1}\right)-2 \tilde{\alpha}\right] \\
& =0.8 u 4 \widetilde{\beta}_{1}^{2} u\left[\left(1-2 \widetilde{\beta}_{1}\right)\left(1+\widetilde{e}_{1}\right)-2 \widetilde{\alpha}\right] \text {. }
\end{aligned}
$$

Note $x_{1}=\alpha, x_{2}=\beta_{1}, x_{3}=\beta_{2}, x_{4}=e_{22}, x_{5}=u$, and $x_{6}=e_{1}$. Note

$$
x_{7}=1+x_{6}-2 x_{1}-2 x_{2}\left(1+x_{6}\right)
$$

Then the optimization model can be simplified to

$$
\begin{aligned}
\max & Y \\
& =\max -x_{1}+\left(1-x_{2}\right)\left(1+x_{6}\right)
\end{aligned}
$$




$$
\begin{aligned}
&+\left(1-x_{3}\right)\left(1.053+x_{4}\right) \\
& \text { st: } \quad x_{2}-x_{6}+\frac{0.6 x_{3}\left(0.053+x_{4}\right)\left(1-2 x_{2}\right)}{x_{5} x_{7}^{2}} \\
&+\frac{\left(0.053+x_{4}\right) 62}{x_{5} x_{7}^{2}} \\
& 0.4 x_{3} x_{5} x_{7}-\left(0.053+x_{4}\right)=0 \\
& x_{1}+x_{2}\left(1+x_{6}\right)+0.6 x_{3}\left(1+\frac{0.053+x_{4}}{x_{5} x_{7}}\right) \\
& \quad-0.5 x_{6}^{2}-0.5\left(\frac{0.053+x_{4}}{x_{5} x_{7}}\right)^{2}-2 x_{2}^{2} \\
& \quad-0.72 x_{3} 62=0.4 \\
& x_{7}=1+x_{6}-2 x_{1}-2 x_{2}\left(1+x_{6}\right) .
\end{aligned}
$$

If second constraints are deformed, that is, $0.053+x_{4}=$ $0.4 x_{3} x_{5} x_{7}$, then after simplification they are as follows:

$$
\begin{aligned}
\max \quad & \\
= & \max -x_{1}+\left(1-x_{2}\right)\left(1+x_{6}\right) \\
& +\left(1-x_{3}\right)\left(1+0.4 x_{3} x_{5} x_{7}\right) \\
\text { st: } \quad & x_{2}-x_{6}+\frac{0.24 x_{3}^{2}\left(1-2 x_{2}\right)}{x_{7}}+\frac{0.16 x_{3}^{2}}{x_{7}}=0 \\
& x_{1}+x_{2}\left(1+x_{6}\right)+0.6 x_{3}-0.5 x_{6}^{2}-0.56 x_{3}^{2} \\
& -2 x_{2}^{2}=0.4 \\
& x_{7}=1+x_{6}-2 x_{1}-2 x_{2}\left(1+x_{6}\right) .
\end{aligned}
$$

If still second constraints are deformed, that is,

$$
\begin{aligned}
x_{1}= & -x_{2}\left(1+x_{6}\right)-0.6 x_{3}+0.5 x_{6}^{2}+0.56 x_{3}^{2}+2 x_{2}^{2} \\
& +0.4
\end{aligned}
$$

then after simplification they are as follows:

$$
\begin{array}{ll}
\max \quad Y & \\
= & \max 0.5+0.5 x_{6}+0.5 X_{7} \\
& +\left(1-x_{3}\right)\left(1+0.4 x_{3} x_{5} x_{7}\right) \\
\text { st: } & x_{2}-x_{6}+\frac{0.4 x_{3}^{2}-0.48 x_{2} X_{3}^{2}}{x_{7}}=0 \\
& x_{7}=1+x_{6}-2 x_{1}-2 x_{2}\left(1+x_{6}\right) .
\end{array}
$$

According to the constraint conditions, we can construct the following equation with $x_{3}$ as the center:

$$
\begin{array}{r}
\left(0.4-1.6 x_{2}-1.12 x_{6}\right) x_{3}^{2}+1.2\left(x_{2}-x_{6}\right) x_{3} \\
+\left(x_{2}-x_{6}\right)\left(0.2+x_{6}-x_{6}^{2}-4 x_{2}^{2}\right)=0 .
\end{array}
$$

According to the above conditions, the value of other variables can be calculated according to $x_{2}$ and $x_{6}$, and then the optimal solution can be obtained by simulation with the Matlab.

\section{Competing Interests}

The authors declare that there are no competing interests regarding the publication of this paper.

\section{Acknowledgments}

The authors acknowledge the financial support by the National Natural Science Foundation of China (no. 71671142 and no. 71603212), by Humanities and Social Science Project of Ministry of Education of China (14XJCZH001), by Social Science Planning Project of Sichuan Province (SC14A030), and by Soft Science Research Project of Sichuan Province (2016ZR0254). The authors also thank their students Xiangyi Liao and Litian $\mathrm{Xu}$ who contributed to this article.

\section{References}

[1] Y. F. Li and Z. F. Zhou, "An incentive contract model for venture capitalist based on the principal-agent relationship," Chinese Journal of Management, vol. 8, no. 6, pp. 872-878, 2011 (Chinese).

[2] C. Casamatta, "Financing and advising: optimal financial contracts with venture capitalists," Journal of Finance, vol. 58, no. 5, pp. 2059-2085, 2003.

[3] K. M. Schmidt, "Convertible securities and venture capital finance," The Journal of Finance, vol. 58, no. 3, pp. 1139-1166, 2003.

[4] Q. Yang and Y. Li, "An analysis of double moral hazard and the optimal contract in venture investment," Systems Engineering, vol. 22, no. 11, pp. 71-73, 2004.

[5] J.-J. Zheng, P. Zhang, X.-S. Hu, and W.-L. Jiang, "Research on bidding strategy and modeling of equity auction based on stochastic differential equations," System Engineering Theory and Practice, vol. 33, no. 4, pp. 893-900, 2013.

[6] J. J. Zheng, X. Tan, and W. T. Fan, "An incentive model with stocks based on principal-agent theory," Journal of Management Sciences in China, vol. 8, no. 1, pp. 24-29, 2005.

[7] J. J. Zheng and H. Liu, "Study on the incentive model between the venture investor and the venture capitalist based on the principal-agent relationship," The Journal of Quantitative and Technical Economics, vol. 8, no. 5, pp. 151-156, 2005.

[8] W. X. Guo and Y. Zeng, "Doublemoral hazard and the theory of capital structure of venture capital financing," Journal of Management Sciences in China, vol. 12, no. 3, pp. 119-131, 2009.

[9] J.-P. Xu and S.-J. Chen, "Study of venture capital's principalagent model based on asymmetric information," System Engineering Theory and Practice, vol. 24, no. 1, pp. 19-24, 2004.

[10] Y. Chan, D. Siegel, and A. V. Thakor, "Learning, corporate control and performance requirements in venture capital contracts," International Economic Review, vol. 31, no. 2, pp. 365381, 1990.

[11] Y.-H. Jin, Y.-Q. Xi, and Z.-X. Ye, "Study of multi-period dynamic financial model of venture capital considering reputation," 
System Engineering Theory and Practice, vol. 23, no. 8, pp. 7680, 2003.

[12] J. Xu, A. M. Wang, and H. M. Chen, "Research on control right incentive mechanism of venture capital based on reputation," Journal of Industrial Engineering/Engineering Managemen, vol. 21, no. 3, pp. 67-71, 2007.

[13] R. Y. Ying and Y. Q. Zhao, "An analysis of incentive mechanism and agent cost in venture capital," Journal of Finance and Economics, vol. 30, no. 6, pp. 22-29, 2004.

[14] W. A. Sahlman, "The structure and governance of venture-capital organizations," Journal of Financial Economics, vol. 27, no. 2, pp. 473-521, 1990.

[15] A. Shliefer and R. Vishy, "Liquidation values and debt capacity: a market equilibrium approach," The Journal of Finance, vol. 47, no. 4, pp. 1343-1366, 1992.

[16] G. Y. Ai, J. Xu, and Y. Yu, “The reputation incentive mechanism of venture capital investment under relative performance evaluation," Journal of Shanghai Jiao Tong University, vol. 41, no. 7, pp. 1134-1137, 2007.

[17] R. Elitzur and A. Gavious, "A multi-period game theoretic model of venture capitalists and entrepreneurs," European Journal of Operational Research, vol. 144, no. 2, pp. 440-453, 2003.

[18] S. D. Zhang and D. X. Wei, "Analysis on multi-stage investment game of double moral hazard in venture capital," Nankai Economics Studies, vol. 6, pp. 142-150, 2008.

[19] D. J. L. Kahneman and R. T. Knetsch, "Fairness and the assumptions of economics part 2," The Behavioral Foundations of Economic Theory, vol. 59, no. 4, pp. 285-300, 1986.

[20] E. Fehr and K. M. Schmidt, "A theory of fairness, competition, and cooperation," Quarterly Journal of Economics, vol. 114, no. 3, pp. 817-868, 1999.

[21] M. Rabin, "Incorporating fairness into game theory and economics," American Economic Review, vol. 83, no. 5, pp. 12811302, 1993.

[22] J. J. Zheng and M. Y. Xu, "A research into venture financing contract on the basis of fairness preference," Economic Review, vol. 1, pp. 14-18, 2010.

[23] T. L. Feng, J. Gu, and R. T. Jing, "Motivation of entrepreneur's self-owned capital and incentive factors on venture capitalist," Journal of Systems and Management, vol. 18, no. 5, pp. 500-505, 2009.

[24] Y. F. Li and Z. F. Zhou, "Study on the incentive contract model for venture capital based on over confidence and monitoring," Forecasting, vol. 30, no. 4, pp. 48-54, 2011.

[25] C. Ding, "A comparative study of marketing channel principalagent model based on entirely rational and fairness preference," Journal of Industrial Engineering/Engineering Management, vol. 28, no. 1, pp. 185-194, 2014.

[26] J. J. Zheng and J. F. Wu, "Research on moral hazard of venture entrepreneur base on the fairness preference," Technology Economics, vol. 29, no. 8, pp. 88-92, 2010.

[27] A. D. Bruyn and G. E. Bolton, "Estimating the influence of fairness on bargaining behavior," Management Science, vol. 54, no. 10, pp. 1774-1791, 2008.

[28] C. H. Loch and Y. Wu, "Social preferences and supply chain performance: an experimental study," Management Science, vol. 54, no. 11, pp. 1835-1849, 2008.

[29] T. H. Cui, J. S. Raju, and Z. J. Zhang, "Fairness and channel coordination," Management Science, vol. 53, no. 8, pp. 1303-1314, 2007.
[30] Z. H. Sheng, The Stackelberg Decision Theory, Science Press, Beijing, China, 1998.

[31] Z. H. Sheng and D. P. Jiang, Evolution Economics, Sanlian Press, Shanghai, China, 2002.

[32] Y. J. Pu, "A model incorporating fairness into principal-agent: a contribution from behavior economics," Contemporary Finance and Economics, vol. 268, no. 3, pp. 5-11, 2007.

[33] Y. J. Pu, "A principal-agent model with fairness," China Economic Quarterly, vol. 7, no. 1, pp. 298-318, 2007. 


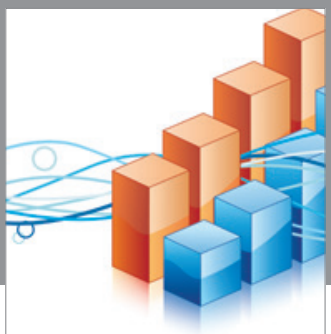

Advances in

Operations Research

vatem alat4

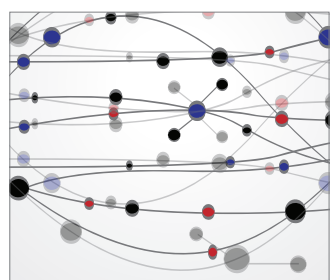

\section{The Scientific} World Journal
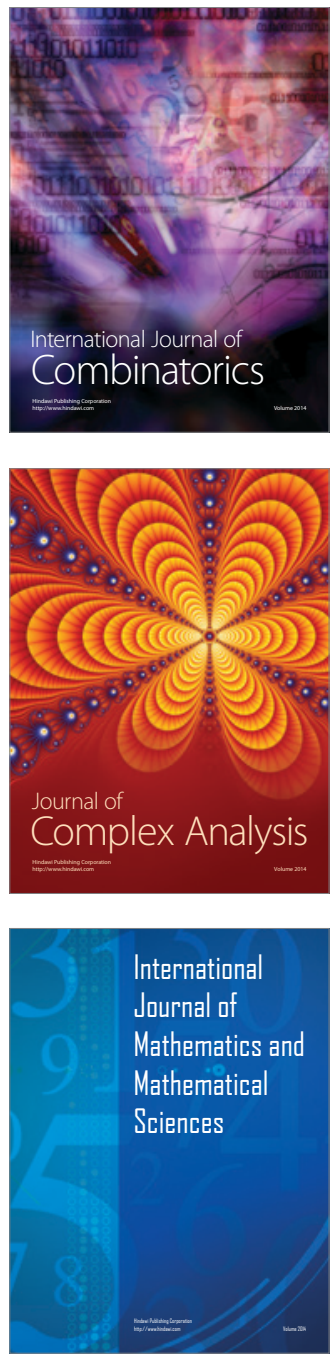
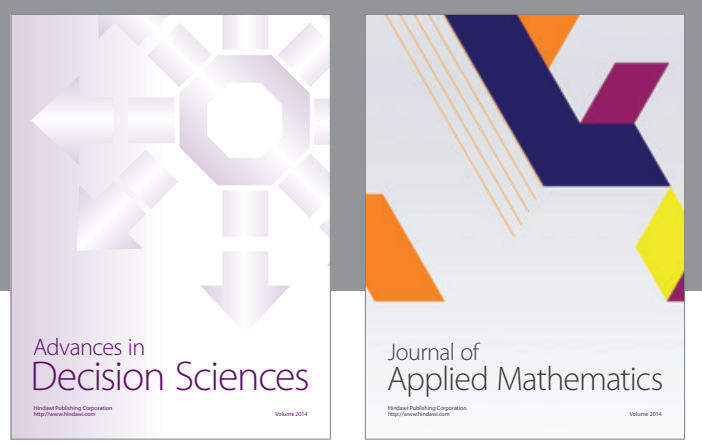

Algebra

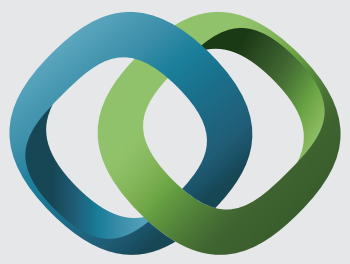

\section{Hindawi}

Submit your manuscripts at

http://www.hindawi.com
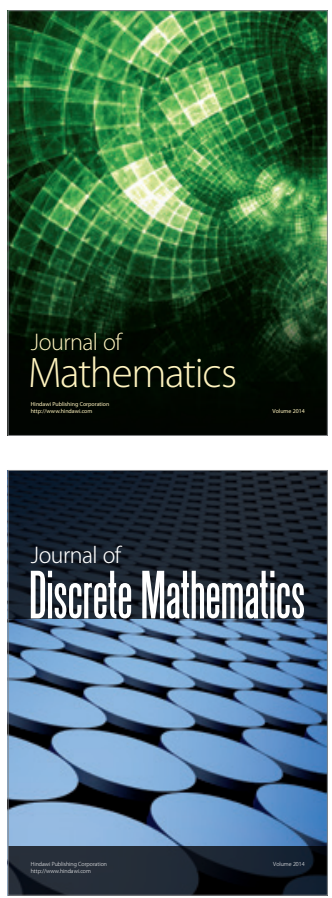

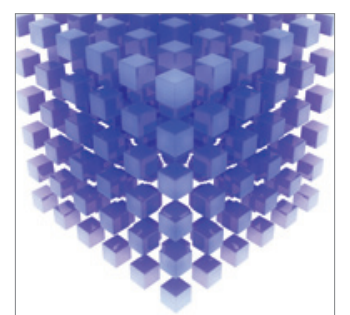

Mathematical Problems in Engineering
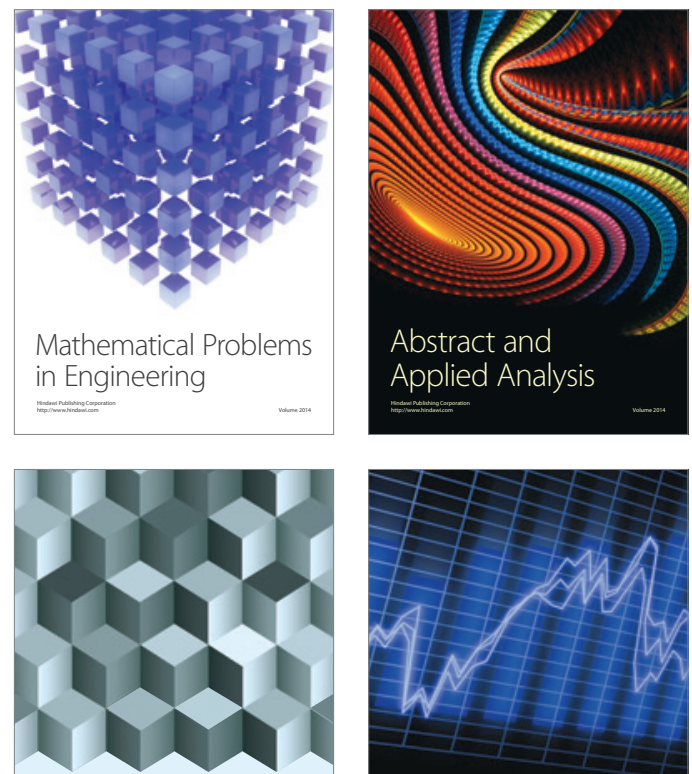

Journal of

Function Spaces

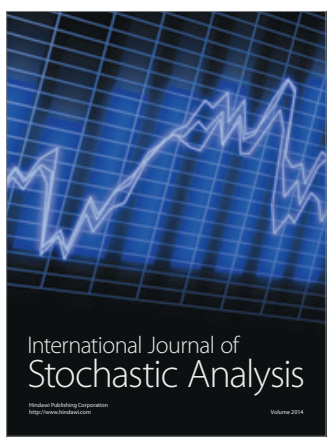

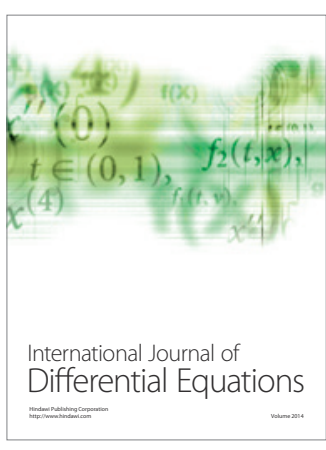
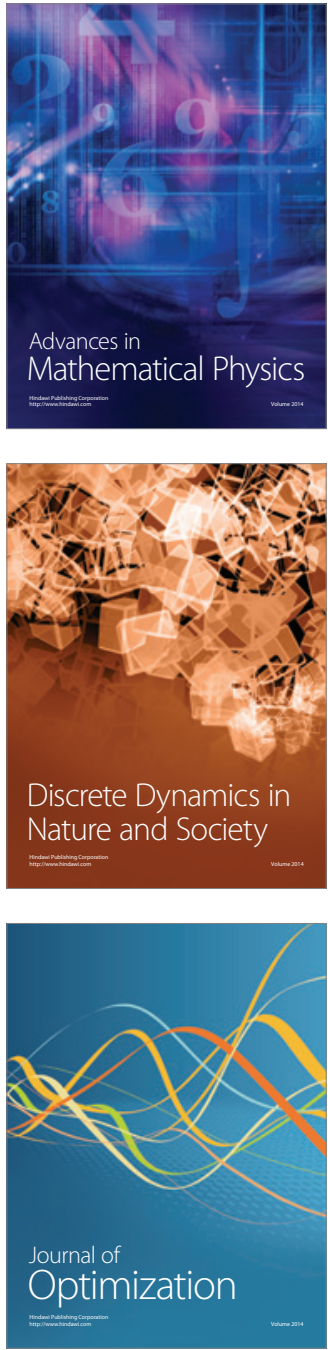